\title{
DURASI MENYUSUI, DUKUNGAN KELUARGA DAN PENGETAHUAN MEMPENGARUHI PERILAKU IBU DALAM PEMBERIAN ASI EKSKLUSIF DI PUSKESMAS MALEI KABUPATEN POSO
}

\author{
The effect of breastfeeding duration, family support and knowledge towards mother \\ behavior during exclusive breastfeeding in malei community health center poso
}

\author{
Abdul Malik Lawira \\ Poltekkes Kemenkes Palu \\ (malikikimlawira@gmail.com, 081354532898)
}

\begin{abstract}
ABSTRAK
Penelitian ini bertujuan untuk mengidentifikasi faktor-faktor yang dapat memepengaruhi perilaku ibu dalam pemberian ASI Eksklusif pada bayi usia 0-6 bulan di wilayah kerja Puskesmas Malei Kabupaten Poso. Desain penelitian observasional analitik rancangan Cross Sectional, semua anggota populasi dijadikan sampel sebanyak 82 reponden dari ibu yang mempunyai bayi usia 6-12 bulan. Alat pengumpulan data berupa kuesioner dan teknik analisa data yaitu data univariat dan data bivariat. Hasil Penelitian menunjukkan faktor umur $(\mathrm{p}=0,158)$, pendidikan $(\mathrm{p}=0,360)$ dan pekerjaan $(\mathrm{p}=0,543)$ tidak memiliki hubungan yang bermakna dengan perilaku pemberian ASI eksklusif, sedangkan faktor durasi menyusui $(\mathrm{p}=0,007)$, dukungan keluarga $(\mathrm{p}=0,005)$ dan pengetahuan $(\mathrm{p}=0,005)$ memiliki hubungan yang bermakna dengan perilaku pemberian ASI eksklusif di wilayah kerja Puskesmas Malei Kabupaten Poso. Kesimpulan, durasi menyusui, dukungan keluarga dan pengetahuan memiliki hubungan dengan perilaku pemberian ASI Eksklusif di Wilayah Kerja Puskesmas Malei Kabupaten Poso. Perlu meningkatkan dukungan keluarga dan durasi oleh setiap ibu menyusui. Memberikan pengetahuan tentang pemberian ASI Ekslusif pada kegiatan antenatal dan dukungan laktasi pascanatal baik di rumah sakit maupun di puskesmas hingga enam bulan setelah melahirkan.
\end{abstract}

Kata kunci : Durasi menyusui, Dukungan keluarga, pengetahuan, ASI Eksklusif

\section{ABSTRACT}

This research aims to identify factors that can effect the behavior of mothers during exclusive breastfeeding for infants aged 0-6 months in Malei Community Health Center in Poso. The design of this research is observational analytic with Cross Sectional design. The sample of 82 respondents, who were the total of population, consisted of mothers who had babies aged 6-12 months. Data collection tool was questionnaires and techniques of data analysis were univariate data and bivariate data. The results showed age factors $(p=0.158)$, education $(p=0.360)$ and employment $(p=0.543)$, did not have a meaningful relationship on exclusive breastfeeding behavior. While the duration of breastfeeding factors $(p=0.007)$, family support $(p=0.005)$ and knowledge $(p=0.005)$, have a significant relationship with exclusive breastfeeding behavior in Malei Community Health Center, Poso. Conclusions, the duration of breastfeeding factors, family support and knowledge, have a relationship towards mother's exclusive breastfeeding behavior in Malei Community Health Center, Poso Regency. Thus, this study suggests to increase family support and duration of breastfeeding for each mother and providing knowledge about exclusive breastfeeding for antenatal activities and postnatal lactation support, both at the hospital and at the community health center up to six months after giving birth.

Keywords: Duration of breastfeeding, Family support, knowledge, Exclusive breastfeeding 


\section{PENDAHULUAN}

Keputusan Menteri Kesehatan Nomor 450/MENKES/SK/VI/2004 tentang pemberian ASI Ekskusif di Indonesia menjelaskan bahwa pemberian ASI eksklusif selama 6 bulan kemudian dilanjutkan sampai anak berumur 2 tahun atau lebih diiringi dengan makanan tambahan yang sesuai. Hal tersebut sesuai dengan alternatif solusi yang diberikan World Health Organization (WHO) dan United Nation Children Fund (UNICEF) yaitu anak sebaiknya diberi ASI minimal selama 6 bulan guna menurunkan angka kesakitan dan kematian anak. Peraturan Pemerintah Republik Indonesia Nomor 33 Tahun 2012 tentang Pemberian Air Susu Ibu Eksklusif juga menjelaskan bahwa ASI merupakan cairan hasil sekresi kelenjar payudara ibu. ASI eksklusif yaitu memberikan ASI saja kepada bayi mulai dilahirkan sampai enam bulan tanpa melakukan penambahan dan/atau penggantian dengan makanan atau minuman lain ${ }^{(1)}$.

Penelitian Susiloretni dkk menyatakan bahwa ibu dengan tingkat pengetahuan menyusui yang tinggi memiliki durasi pemberian ASI eksklusif yang tinggi juga. Ibu yang memiliki skor pengetahuan> 80 memiliki peluang $73 \%$ lebih besar dari memberikan ASI eksklusif dibandingkan dengan ibu yang memiliki skor pengetahuan <60. Faktor-faktor yang memperpendek durasi pemberian ASI eksklusif adalah kurangnya dukungan nenek untuk pemberian ASI eksklusif, menerima sampel formula yang dibuang dan pengalaman ibu yang mengalami pembengkakan payudara.
Pengetahuan menyusui ibu yang tinggi adalah satu-satunya faktor yang terkait dengan durasi pemberian ASI eksklusif yang lebih lama ${ }^{(2)}$. Penelitian Tarigan dkk menunjukkan bahwa faktor pemicu dalam pemberian ASI Eksklusif kepada bayi adalah pengetahuan, sikap, dan perilaku ibu. Dalam penelitian tersebut sebagian besar ibu masih belum paham tentang manfaat pemberian ASI Eksklusif. Faktor pekerjaan, pendidikan juga sebagai pemicu untuk terjadinya pemberian ASI Eksklusif kepada bayinya. Faktor lain pemberian ASI Eksklusif adalah inisiasi menyusu dini, tempat melahirkan, dan ketersediaan ruangan untuk menyusui. Status kesehatan ibu, dukungan keluarga dan petugas yang menolong persalinan sebagai faktor penguat untuk pemberian ASI Eksklusif kepada bayi ${ }^{(3)}$.

Penelitian Rahmadani di Medan menunjukkan bahwa dukungan yang diterima ibu hamil dari orang tua \& petugas kesehatan berperan dalam kesuksesan ASI Eksklusif, demikian pula dengan pengetahuan, sikap dan perilaku $^{(4)}$. Hasil penelitian Wowor dkk di Manado juga menunjukkan bahwa ada hubungan pengetahuan dan sikap dengan pemberian $\mathrm{ASI}^{(5)}$. Penelitian Sholikah menunjukkan bahwa penolong persalinan memiliki hubungan yang signifikan dengan perilaku ibu dalam pemberian ASI eksklusif. Inisisasi menyusu dini memiliki hubungan yang signifikan dengan perilaku ibu dalam pemberian ASI eksklusif namun dukungan petugas kesehatan tidak memiliki hubungan dengan perilaku ibu dalam pemberian ASI 
eksklusif $^{(1)}$. Penelitian Safitri di Cibeber menunjukkan bahwa kondisi fisiologis payudara ibu saat menyusui memungkinkan bayi mendapatkan ASI eksklusif, sedangkan kebiasaan pemberian makanan prelakteal tidak memungkinkan ibu untuk memberikan ASI eksklusif. Dukungan keluarga juga belum maksimal dalam memberikan kontribusi yang positif kepada ibu untuk memberikan ASI eksklusif $^{(6)}$.

Namun hasil penelitian Zuhana dkk di Pekalongan menunjukkan bahwa $70 \%$ responden penelitian tidak memberikan ASI eksklusif dimana faktor pendidikan, pekerjaan, sikap, tenaga kesehatan dan keluarga tidak ada hubungan yang signifikan dengan pemberian ASI eksklusif ${ }^{(7)}$. Penelitian Haryani dkk di Kota Mataram Propinsi Nusa Tenggara Barat menunjukkan bahwa alasan ibu bekerja tidak memberikan ASI tidak eksklusif pada bayinya disebabkan karena adanya rasa repot dari ibu, karena tuntutan beban kerja yang tinggi, waktu cuti yang sedikit, sarana prasarana yang kurang seperti belum tersedianya TPA dan kurir ASI dan adannya tuntutan kebutuhan ekonomi keluarga $^{(8)}$.

Pemberian ASI eksklusif di luar negeri seperti penelitian di Amerika Serikat menunjukan bahwa dari 2.149 ibu yang menyusui sebesar $70 \%$ mengulangi durasi menyusui eksklusif anak pertama mereka untuk anak kedua mereka $14 \%$ wanita mengulang pemberian ASI Eksklusif $\geq 4$. Usia ibu yang lebih tua dan menikah terkait dengan peningkatan durasi pemberian ASI eksklusif ${ }^{(9)}$.
Penelitian Agho dkk di Nigeria menunjukkan bahwa tingkat pemberian ASI Eksklusif rata-rata di antara bayi di bawah 6 bulan adalah $16,4 \%$ dan menurun hingga $7,1 \%$ pada bayi di usia bulan kelima. Ibu yang memiliki empat atau lebih kunjungan antenatal secara signifikan lebih cenderung terlibat dalam pemberian ASI eksklusif. Proporsi bayi perempuan disusui secara eksklusif daripada bayi laki-laki(10). Penelitian Jahanpour di Tanzania menunjukkan tren pemberian ASI eksklusif meningkat selama 12 tahun periode tahun 2002-2014 ${ }^{(11)}$.

Profil Kesehatan Sulteng menunjukkan bahwa di Sulawesi Tengah jumlah bayi yang diberi ASI Eksklusif sebesar 36,2\% dari 18.940. sedangkan ASI Eksklusif Kabupaten Poso sebesar 41,5\% dari 1.728 anak bayi 0-6 bulan. Wilayah Puskesmas Malei Kecamatan Lage Kabupaten Poso terdiri dari 11 desa, 10 Posyandu dan 10 Poskesdes dengan cakupan ASI Eksklusif di bulan November 2017 adalah 82 bayi. Berdasarkan hasil studi pendahuluan selama bulan November-Desember 2017 di Puskesmas Malei Kabupaten Poso ada 81 ibu yang mempunyai bayi 0-6 bulan, yang memberikan ASI Eksklusif hanya 60 bayi sisanya 21 bayi ibu memberikan pengganti Air Susu Ibu (PASI) atau juga susu formula. Hal ini sangat disebabkan karena ibu bekerja, ada juga ibu tidak memberikan ASI karena ibu merasa sudah memberikan susu formula. Padahal dampak bila bayi tidak diberikan ASI Eksklusif dapat menurunkan berat badan bayi, bayi juga akan mudah sakit karena tidak dapat 
zat immunoglobulin yang terkandung dalam kolostrum. Pemberian susu formula pada bayi baru lahir bisa menyebabkan alergi karena merangsang aktivitas sistem Ige yang ada pada bayi baru lahir belum sempurna, sedangkan dalam jangka panjang anak akan mudah kekurangan gizi dan obesitas.

Bervariasinya faktor pengaruh pemberian ASI eksklusif antar wilayah mendasari peneliti untuk melakukan penelitian di Poso. Tujuan penelitian ini untuk mengidentifikasi faktorfaktor yang dapat mempengaruhi perilaku ibu dalam pemberian ASI Eksklusif pada bayi usia 0-6 bulan di Wilayah Kerja Puskesmas Malei Kabupaten Poso.

\section{METODE PENELITIAN}

Desain penelitian observasional analitik dengan rancangan Cross Sectional dilaksanakan di wilayah kerja Puskesmas Malei Kabupaten Poso pada Bulan Juni 2018 sampai Agustus 2018. Populasi sebanyak 82 reponden dari ibu yang mempunyai bayi usia 6-12 bulan berada di wilayah kerja Puskesmas Malei Kabupaten Poso. Teknik sampling yaitu total sampling dimana semua populasi dijadikan sampel yaitu berjumlah 82 responden. Alat pengumpulan data berupa kuesioner dan teknik analisa data yaitu data univariat dan data bivariat menggunakan cross tabulating.

\section{HASIL}

Sebelum penelitian ini dilaksanakan terlebih dahulu telah dilakukan uji coba kuesioner yang digunakan dengan uji vadility
Nilai korelasi variabel independen terhadap variabel dependen dapat dilihat pada tabel 1 berikut;

Tabel 1. Nilai korelasi variabel independen terhadap variabel dependen (hasil uji coba kuesioner sebagai kontrol kualitas)

\begin{tabular}{lcc}
\hline \multicolumn{1}{c}{$\begin{array}{c}\text { Variabel } \\
\text { Independen } \\
(\mathbf{X})\end{array}$} & $\begin{array}{c}\text { Nilai korelasi } \\
\text { dengan } \\
\text { variabel } \\
\text { perilaku } \\
\text { pemberian ASI } \\
\text { Eksklusif (Y) }\end{array}$ & p-value \\
\hline Pendidikan & 0,623 & 0,003 \\
Durasi menyusui & 0,537 & 0,005 \\
Dukungan keluarga & 0,336 & 0,037 \\
Pengetahuan & 0,427 & 0,011 \\
\hline
\end{tabular}

Sumber: Data Primer, 2018

Item pertanyaan yang merepresentasikan Variabel pendidikan, durasi menyusui, dukungan keluarga dan pengetahuan memenuhi syarat untuk digunakan sebagai alat ukur dengan nilai $\mathrm{p}=0,005$.

Tabel 2 Karakteristik responden penelitian Pemberian ASI Eksklusif di wilayah kerja Puskesmas Malei Kabupaten Poso tahun 2018

\begin{tabular}{lcc}
\hline \multicolumn{1}{c}{ Karakteristik } & n & \% \\
\hline $\begin{array}{l}\text { Umur (tahun) } \\
<20\end{array}$ & 16 & 19,5 \\
$20-30$ & 40 & 48,8 \\
$31-40$ & 20 & 24,4 \\
$\quad>40$ & 6 & 7,3 \\
Pendidikan & & \\
$\quad$ Tidak tamat SD & 10 & 12,2 \\
SD & 20 & 24,4 \\
SLTP & 24 & 29,3 \\
SLTA & 20 & 24,4 \\
PT & 8 & 9,8 \\
Pekerjaan & & \\
PNS & 34 & 41,5 \\
Wiraswasta & 26 & 31,7 \\
Tani & 9 & 11,0 \\
IRT & 13 & 15,9 \\
\hline Total & 82 & 100 \\
\hline Sil : Data & &
\end{tabular}

Sumber : Data primer, 2018 
Tabel 2 menunjukan bahwa 40 responden berumur 20-30 tahun sejumlah (48,8\%), berpendidikan SLTP sejumlah 24 responden $(29,3 \%)$ dan bekerja sebagai PNS sebanyak 34 responden $(41,5 \%)$.

Tabel 3 Faktor yang mempengaruhi perilaku ibu dalam pemberian ASI Eksklusif di wilayah kerja Puskesmas Malei Kabupaten Poso tahun 2018

\begin{tabular}{lrrrr}
\hline \multicolumn{1}{c}{ Variabel } & \multicolumn{2}{c}{ Perilaku Pemberian ASI } \\
& $\begin{array}{c}\text { Baik } \\
\mathbf{n = 6 9}\end{array}$ & $\begin{array}{c}\text { Kurang } \\
\mathbf{n}=\mathbf{1 3}\end{array}$ & $\begin{array}{c}\text { Total } \\
\mathbf{n = 8 2}\end{array}$ & p-value \\
\hline Umur & & & & \\
$<20$ & $11(68,8 \%)$ & $5(31,3)$ & 16 & 0,158 \\
$20-30$ & $37(92,5 \%)$ & $3(7,5)$ & 40 & \\
$31-40$ & $16(80,0 \%)$ & $4(20,0)$ & 20 & \\
$>40$ & $5(83,3 \%)$ & $1(16,7)$ & 6 & \\
Pendidikan & & & & \\
Tidak tamatSD & $7(70 \%)$ & $3(30 \%)$ & 10 & 0,360 \\
SD & $15(75 \%)$ & $5(25 \%)$ & 20 & \\
SLTP & $22(91,7 \%)$ & $2(8,3 \%)$ & 24 & \\
SLTA & $18(90 \%)$ & $2(10 \%)$ & 20 & \\
PT & $7(87,5 \%)$ & $1(12,5 \%)$ & 8 & \\
Pekerjaan & & & & \\
PNS & $27(79,4 \%)$ & $7(20,6 \%)$ & 34 & 0,543 \\
Wiraswasta & $24(92,3 \%)$ & $2(7,7 \%)$ & 26 & \\
Petani & $7(77,8 \%)$ & $2(22,8 \%)$ & 9 & \\
IRT & $11(84,6 \%)$ & $2(15,4 \%)$ & 13 & \\
\hline Jumlah & $\mathbf{6 9 ( 8 4 , 1 \% )}$ & $\mathbf{1 3}(\mathbf{1 5 , 9 \% )}$ & $\mathbf{8 2}$ & \\
\hline Sumber : Data Primer, 2018 & & &
\end{tabular}

Pada tabel 3 tabulasi silang antara umur, pendidikan dan pekerjaan ibu terhadap perilaku pemberian ASI Eksklusif menunjukkan ibu yang memberikan ASI eksklusif berada pada kelompok umur yang lebih tua. Berdasarkan uji statistic dengan menggunakan chi-square diperoleh nilai $\mathrm{p}=0,158$. Karena nilai $\mathrm{p}>0,005$ berarti tidak ada hubungan yang signifikan antara umur dengan perilaku pemberian Asi Eksklusif. Sebagian besar pendidikan responden SLTP sebanyak 22 Eksklusif (91,7\%) berperilaku baik dalam pemberian ASI Eksklusif.
Berdasarkan uji statistik dengan menggunakan chi-square diperoleh nilai $\mathrm{p}=0,36$. Karena nilai $\mathrm{p}>0,05$, artinya tidak ada hubungan yang signifikan antara pendidikan dengan perilaku pemberian ASI Eksklusif. Sebagian besar pekerjaan responden wiraswasta sebanyak 24 responden $(92,3 \%)$ berperilaku baik dalam pemberian Asi Eksklusif. Berdasarkan uji statistik dengan menggunakan chi-square diperoleh nilai $p=0,543$. Karena nilai $p>0,005$, artinya tidak ada hubungan yang signifikan antara pekerjaan dengan perilaku pemberian Asi Eksklusif.

Tabel 4 Durasi menyusui, dukungan keluarga dan pengetahuan ibu tentang Pemberian ASI Eksklusif di wilayah kerja Puskesmas Malei Kabupaten Poso tahun 2018

\begin{tabular}{|c|c|c|c|c|}
\hline \multirow[t]{2}{*}{ Variabel } & \multicolumn{3}{|c|}{ Perilaku Pemberian ASI } & \multirow[b]{2}{*}{ p-value } \\
\hline & $\begin{array}{l}\text { Baik } \\
n=69\end{array}$ & $\begin{array}{c}\text { Kurang } \\
n=13\end{array}$ & $\begin{array}{l}\text { Total } \\
n=82\end{array}$ & \\
\hline \multicolumn{5}{|l|}{$\begin{array}{l}\text { Durasi } \\
\text { menyusui }\end{array}$} \\
\hline Sering & $30(88,2 \%)$ & $4(11,8 \%)$ & 16 & 0,007 \\
\hline Kadang-kadang & $23(88,5 \%)$ & $3(11,5 \%)$ & 40 & \\
\hline Jarang & $4(44,4 \%)$ & $5(55,6 \%)$ & 20 & \\
\hline Tidak pernah & $12(92,3 \%)$ & $1(7,7 \%)$ & 6 & \\
\hline \multicolumn{5}{|l|}{$\begin{array}{l}\text { Dukungan } \\
\text { keluarga }\end{array}$} \\
\hline Baik & $56(93,3 \%)$ & $4(6,7 \%)$ & 10 & 0,005 \\
\hline Kurang & $13(59,1 \%)$ & $9(40,9 \%)$ & 20 & \\
\hline \multicolumn{5}{|l|}{ Pengetahuan } \\
\hline Tinggi & $55(91,7 \%)$ & $5(8,3 \%)$ & 34 & 0,005 \\
\hline Rendah & $14(63,6 \%)$ & $8(36,4 \%)$ & 26 & \\
\hline Jumlah & $69(84,1 \%)$ & $13(15,9 \%)$ & 82 & \\
\hline
\end{tabular}

Sumber : Data Primer, 2018

Tabel 4 menunjukkan bahwa semakin sering durasi menyusui semakin baik perilaku menyusuinya. Berdasarkan uji statistik dengan menggunakan chi-square diperoleh nilai $\mathrm{p}=0,007$, karena nilai $\mathrm{p}<0,05$, maka dapat disimpulkan ada hubungan yang signifikan 
antara durasi menyusui dengan perilaku pemberian ASI Eksklusif. Sebagian besar responden sebanyak $56(93,3 \%)$ dukungan keluarga ibu baik. Berdasarkan uji statistik dengan menggunakan chi-square diperoleh nilai $\mathrm{p}=0,005$. Karena nilai $\mathrm{p}<0,05$, maka ada hubungan yang signifikan antara dukungan keluarga ibu dengan perilaku pemberian ASI Eksklusif. Sebagian besar reponden sebanyak 55 (91,7\%) tinggi pengetahuan ibu tentang ASI Eksklusif. Diperoleh uji statistik dengan menggunakan chi-square diperoleh nilai $\mathrm{p}=0,005$. Karena nilai $\mathrm{p}<0,05$, maka dapat disimpulkan hipotesis diterima, artinya ada hubungan yang signifikan antara pengetahuan ibu tentang ASI Eksklusif dengan perilaku pemberian ASI Eksklusif

\section{PEMBAHASAN}

Hasil Penelitian menunjukkan Faktor umur $(\mathrm{p}=0,158)$, pendidikan $(\mathrm{p}=0,360)$ dan pekerjaan $(\mathrm{p}=0,543)$ tidak memiliki hubungan yang bermakna dengan perilaku pemberian ASI Eksklusif, sedangkan faktor durasi menyusui $(\mathrm{p}=0,007)$, dukungan keluarga $(\mathrm{p}=0,005)$ dan pengetahuan $(\mathrm{p}=0,005)$ memiliki hubungan yang bermakna dengan perilaku pemberian ASI Eksklusif di Wilayah Kerja Puskesmas Malei Kabupaten Poso.

Berdasarkan uji statistic chi-square diketahui $\mathrm{p}=$ value 0,36 . Dimana nilai $\mathrm{p}>0,05$ dapat disimpulkan hipotesis ditolak berarti tidak ada hubungan antara pendidikan. Ibu dengan perilaku ibu dalam, pemberian ASI Eksklusif pada bayi 0-6 bulan. Hal ini disebabkan karena sebagian besar pendidikan SLTP sehingga tidak mudah untuk menerima dan mengerti tentang pesan-pesan mengenai pentingnya ASI Eksklusif yang disampaikan oleh petugas kesehatan, atau melalui media massa sehingga diperkirakan ibu balita belum memberikan ASI Eksklusif selama 6 bulan kepada anaknya.

Hasil tersebut sejalan dengan pernyataan bahwa tingkat pendidikan dapat mempengaruhi seseorang termasuk juga perilaku seseorang akan pola hidup terutama memotivasi untuk sikap berperan serta dalam pembangunan pada umumnya makin tinggi pendidikan seseorang makin mudah menerima informasi. Menurut teori Green terdapat 3 faktor yang menentukan perilaku seseorang yaitu factor prediposisi, faktor pendukung, dan faktor pendorong. Berkaitan dengan perilaku ASI Eksklusif salah satu faktor predisposisinya adalah pendidikan ibu. Hasil analisi tersebut diperkuat dengan sebaran bahwa dari 40 responden yang telah menyelesaikan pendidikan wajib (tamat SLTP) memiliki proporsi berperilaku buruk lebih besar yaitu sebanyak $34(85 \%)$, sedangkan 47 reponden yang pendidikan lanjutan memiliki proporsi berperilaku baik lebih besar yaitu sebanyak 33 $(70,2 \%)$.

Hasil penelitian menunjukkan $\mathrm{p}=0,007$ yang berarti ada hubungan yang signifikan antara durasi menyusui dengan perilaku pemberian ASI Eksklusif pada umur 0-6 bulan. Suatu sikap otomatis terwujud dalam suatu tindakan, untuk mewujudkan sikap ibu 
menjadi tindakan memberi ASI secara Eksklusif.

Pengetahuan tentang menyusui merupakan salah satu faktor penentu yang mempromosikan pemberian ASI. Hasil ini konsisten dengan studi Susiloretni yang menunjukkan bahwa tingkat pengetahuan ibu yang rendah tentang menyusui dikaitkan dengan penghentian menyusui eksklusif. Menerima sampel susu formula dari bidan saat dipulangkan mendorong ibu untuk menghentikan pemberian ASI eksklusif Selain itu, ibu menghentikan pemberian ASI eksklusif jika penyedia layanan kesehatan menyarankan penggunaan suplemen formula. Suplementasi formula tanpa pembuktian medis melanggar Kode Pengganti ASI Pemasaran Internasional WHO. Indonesia, seperti negara-negara berpenghasilan menengah lainnya, industri susu formula menyediakan paket sampel formula gratis ke rumah sakit, menawarkan berbagai hadiah kepada tenaga kesehatan, mensponsori kegiatan keagamaan, mendanai seminar untuk para profesional kesehatan, dan melakukan kegiatan kesehatan masyarakat untuk mempromosikan produk mereka.

Studi Susiloretni juga mengkonfirmasi peran negatif dari ibu pada durasi pemberian ASI eksklusif karena mereka cenderung mempromosikan penggunaan makanan lain selain ASI sebelum anak berumur 6 bulan. Tergantung pada pengaturan, peran nenek bisa positif atau negatif pada durasi menyusui. Melibatkan nenek dalam pelatihan atau pendidikan pengasuhan memungkinkan mereka untuk memberikan dukungan yang bermanfaat bagi ibu yang ingin menyusui secara eksklusif. Ibu yang mengalami pembengkakan payudara mengalami beririsiko lebih tinggi menghentikan pemberian ASI eksklusif daripada ibu yang menyusui ekslusif. Wanita yang tidak mengalami kesulitan menyusui seperti pembengkakan payudara, puting yang sakit, puting yang rata, dan mastitis secara eksklusif akan menyusui lebih lama daripada ibu yang mengalami kesulitan menyusui ${ }^{(2)}$.

Pemberian ASI Eksklusif juga dipengaruhi oleh faktor pendukung yang memungkinkan yaitu fasilitas. Fasilitas yang dimaksud lemari pendingin dirumah untuk menyimpan ASI perah, alat pompa untuk memerah ASI. Fasilitas ditempat kerja yang harus ada adalah ruang untuk menyusui, waktu khusus untuk menyusui anaknya, faktor pendukung lainnya adalah dukungan dari suami, keluarga dan mertua. Faktor dukungan keluarga juga berpengaruh karena kebanyakan para ibu tidak memberikan ASI secara eksklusif.

Dalam hal durasi menyusui, penelitian Phillips menunjukkan bahwa banyak wanita cenderung tidak hanya mengulangi durasi pemberian ASI eksklusif anak-anak sebelumnya dengan anak-anak berikutnya, tetapi mengulangi pengalaman yang sebelumnya terjadi pada anak. Dalam penelitian tersebut $14 \%$ dan $13 \%$ wanita secara eksklusif menyusui dua dan tiga anak pertama mereka selama empat atau lebih bulan. 
Mengubah praktik menyusui jarang terjadi daripada pengulangan menyusui, terutama dari perilaku dari tidak pernah menyusui menjadi menyusu eksklusif dan sebaliknya. Penelitian tersebut juga menunjukkan bahwa Ibu yang tidak pernah menyusui anak pertama mereka namun dapat menyusui secara eksklusif anak kedua mereka selama minimal 4 bulan $^{(9)}$.

Hasil penelitian ini menunjukan sebagian besar responden $56(93,3 \%)$ memiliki dukungan keluarga yang baik, berdasarkan uji statistik dengan menggunakan chi-square diperoleh nilai $\mathrm{p}=0,005$. Berarti ada hubungan signifikan antara dukungan keluarga ibu dengan perilaku pemberian ASI Eksklusif. Hasil penelitian ini sejalan dengan penelitian Tarigan dkk yang menyatakan bahwa dukungan keluarga merupakan faktor penguat untuk pemberian ASI Eksklusif kepada bayi ${ }^{(3)}$.

Hasil penelitian ini menunjukan $\mathrm{p}=0,005$ yang berarti ada hubungan yang signifikan antara pengetahuan ibu dengan perilaku pemberian ASI Eksklusif. Hasil penelitian ini sejalan dengan WHO yang menyatakan bahwa pengetahuan dapat membentuk keyakinan tentang sehingga seseorang berperilaku sesuai keyakinan tersebut. Semakin tinggi pengetahuan ibu tentang pentingnya ASI Eksklusif, maka semakin tinggi pula ibu akan berperilaku baik untuk menyusui anaknya secara eksklusif karena salah satu faktor yang mendukung terbentuknya perilaku adalah pengetahuan. Sejalan dengan penelitian Sari dkk yang menunjukkan bahwa terdapat hubungan yang bermakna antara pengetahuan responden dengan pemberian ASI eksklusif pada bayi hingga umur 6 bulan bagi ibu yang bekerja di Desa Sumberejo Kecamatan Mranggen Kabupaten Demak ${ }^{(12)}$.

Hasil penelitian Mukhoirotin menunjukkan ada hubungan pengetahuan ibu tentang ASI Eksklusif dengan perilaku pemberian ASI Eksklusif dengan nilai signifikansi $\mathrm{p}=0,003$. Perilaku pemberian ASI secara Eksklusif dapat berjalan maksimal bila didasari pengetahuan yang baik. Oleh karena itu, diharapkan petugas juga berperan aktif dalam memberikan informasi tentang ASI Eksklusif sehingga pemberian ASI eksklusif dapat berjalan maksimal ${ }^{(13)}$.

Namun penelitian ini berbeda dengan hasil yang ditemukan oleh Sartono dkk yang menyatakan bahwa pengetahun ibu, pendidikan ibu dan dukungan suami secara terpisah maupun bersamaan tidak berhubungan dengan praktek pemberian ASI eksklusif. Praktek pemberian ASI eksklusif lebih ditentukan oleh keinginan pribadi ibu dan keberhasilan manajemen laktasi pada saat pertolongan persalinan di institusi pelayanan kesehatan, yang sangat diwarnai oleh komitmen petugas kesehatan penolong persalinan terhadap program peningkatan ASI Eksklusif $^{(14)}$.

Penelitian Su dkk menunjukkan bahwa wanita yang menerima perawatan rutin dalam kelompok pendukung pascanatal cenderung menyusui secara eksklusif pada dua minggu hingga pada enam bulan setelah kelahiran. Wanita yang menerima pendidikan antenatal 
menyusui secara eksklusif pada enam minggu hingga enam bulan pasca melahirkan. Pendidikan pemberian ASI antenatal dan dukungan laktasi pascanatal, karena intervensi tunggal yang berbasis di rumah sakit keduanya secara signifikan meningkatkan tingkat pemberian ASI eksklusif hingga enam bulan setelah melahirkan. Dukungan pascanatal sedikit lebih efektif daripada pendidikan antenatal $^{(15)}$.

\section{KESIMPULAN DAN SARAN}

Faktor durasi menyusui, dukungan keluarga dan pengetahuan memiliki hubungan dengan perilaku pemberian ASI Eksklusif di Wilayah Kerja Puskesmas Malei Kabupaten Poso. Perlu meningkatkan dukungan keluarga dan durasi menyusui oleh setiap ibu. Memberikan pengetahuan tentang pemberian ASI Ekslusif pada kegiatan antenatal dan dukungan laktasi pascanatal, baik di rumah sakit maupun di puskesmas hingga enam bulan setelah melahirkan.

\section{DAFTAR PUSTAKA}

1. Sholikah BM. Hubungan Penolong Persalinan, Inisiasi Menyusu Dini dan Dukungan Petugas Kesehatan dengan Perilaku Ibu dalam Pemberian ASI Eksklusif. J Keperawatan Muhammadiyah. 2018;3(2):6-12.

2. Susiloretni KA, Hadi H, Prabandari YS, Soenarto YS, Wilopo SA. What Works to Improve Duration of Exclusive Breastfeeding: Lessons from the Exclusive Breastfeeding Promotion Program in Rural Indonesia. Matern Child Health J [Internet]. 2015;19(7):1515-25. Available from: http://dx.doi.org/10.1007/s10995-014-1656-z

3. Tarigan IU, Aryastami N. Pengetahuan, Sikap dan Perilaku Ibu Bayi terhadap Pemberian ASI Ekslusif. Bul Penelit Sist Kesehat. 2012;15:390-7.

4. Rahmadani S, Syahrial E, Andayani LS. Perilaku ibu hamil yang berkunjung ke puskesmas dalam manajemen laktasi untuk keberhasilan pemberian ASI eksklusif di wilayah kerja Puskesmas Padang Bulan Kota Medan tahun 2012. Kebijakan, Promosi Kesehat dan Biostatiskik [Internet]. 2013;2(1):1-9. Available from: https://jurnal.usu.ac.id/index.php/kpkb/article/ view/1332

5. Wowor M, Laoh JM, Pangemanan DH. Hubungan pengetahuan dan sikap dengan pemberian asi eksklusif pada ibu menyusui di puskesmas bahu kota manado. Ejurnal Keperawataan (e-Kp) [Internet]. 2013;1(1):17. Available from: https://ejournal.unsrat.ac.id/index.php/jkp/arti cle/download/2199/1757

6. Safitri Y, Minsarnawati. Perilaku yang menghambat pemberian ASI eksklusif pada ibu di wilayah Kerja Puskesmas Cibeber Tahun 2009. J Kesehat Reproduksi. 2012;3(3):161-9.

7. Zuhana N, Izzah N, Rusmariana A. Faktorfaktor yang mempengaruhi perilaku pemberian ASI eksklusif pada ibu menyusui di Kecamatan Wonopringgo Kabupaten Pekalongan. J Ilm Kesehat. 2007;1(1):1-4.

8. Haryani, Wulandari1 LL, Karmaya M. Alasan Tidak Diberikan ASI Eksklusif oleh Ibu Bekerja di Kota Mataram Nusa Tenggara Barat. Public Heal Prev Med Arch. 2014;2(2):162-8.

9. Phillips G, Brett K, Mendola P. Previous breastfeeding practices and duration of exclusive breastfeeding in the United States. Matern Child Health J. 2011;15(8):1210-6.

10. Agho KE, Dibley MJ, Odiase JI, Ogbonmwan SM. Determinants of exclusive breastfeeding in Nigeria. BMC Pregnancy Childbirth [Internet]. 2011;11(2):2-8. Available from: http://www.biomedcentral.com/14712393/11/2

11. Jahanpour O, Msuya SE, Todd J, Straypedersen B, Mgongo M. Increasing trend of exclusive breastfeeding over 12 years period ( 2002 - 2014 ) among women in Moshi , Tanzania. 2018;7:1-9.

12. Sari I, Mulyono B, Andarsari W. Hubungan Tingkat Pengetahuan Ibu Bekerja Dengan Pemberian Asi Eksklusif Di Desa Sumberejo Kecamatan Mranggen Kabupaten Demak Tahun 2011. J Kebidanan [Internet]. 2012;1(1). Available from: portalgaruda.org/download_article.php?article $=3325 \%$ Ahttp://digilib.unimus.ac.id

13. Mukhoirotin, Khusniyah Z, Susanti L. Hubungan Pengetahuan Ibu Tentang ASI Eksklusif dengan Perilaku Pemberian ASI Eksklusif di BPM Hj. Umi Salamah 
Peterongan Jombang. J Edu Heal. 2015;5(2):94-101.

14. Sartono A, Utaminingrum H. Hubungan Pengetahuan Ibu, Pendidikan Ibu dan Dukungan Suami dengan Praktek Pemberian Asi Eksklusif di Kelurahan Muktiharjo Kidul Kecamatan Telogosari Kota Semarang. J Gizi Univ Muhamadiyah Semarang [Internet]. 2012;1(1):1-9. Available from: http://jurnal.unimus.ac.id/index.php/jgizi/articl e/view/565

15. Su LL, Chong YS, Chan YH, Chan YS, Fok $\mathrm{D}$, Tun KT, et al. Antenatal education and postnatal support strategies for improving rates of exclusive breast feeding: Randomised controlled trial. $\mathrm{Br}$ Med J. 2007;335(7620):596-9. 